\title{
"La narración alivia la pesadilla de la historia" \\ La ciudad ausente de Ricardo Piglia y la periferia de la distopía
}

Recibido: 17/09/2018 | Revisado: 22/10/2018 |Aceptado: 16/11/2018

DOI: 10.17230/co-herencia.16.30.6

Efrén Giraldo*

egiral25@eafit.edu.co

Resumen Este artículo examina la aparición de motivos distópicos en la obra de Ricardo Piglia. Se discuten las afirmaciones sobre narración y poder en "Teoría del complot" y otros ensayos del autor, y las referencias a poder policial y narración en Los diarios de Emilio Renzi y La ciudad ausente. Esto, para señalar que Piglia adelanta una lectura distópica de la historia argentina y latinoamericana. Tal lectura tiene sus bases visuales y narrativas en una tradición novelística y cinematográfica distópica que no ha sido suficientemente reconocida en los trabajos sobre el escritor argentino. Con la reciente publicación de los Diarios y la aparición póstuma de libros de conferencias y entrevistas de Piglia, esa línea de lectura cobra relevancia.

\section{Palabras clave:}

Distopía, literatura latinoamericana contemporánea, narración, poder, ciencia ficción, complot, memoria, vigilancia.

\section{"Narration alleviates the nightmare of History" La ciudad ausente by Ricardo Piglia and the periphery of dystopia}

\begin{abstract}
This article examines dystopian motifs in Ricardo Piglia's work. Assertions on narration and power are discussed in "Teoría del complot" and other essays by the author, also, police power and narration is analyzed in Los diarios de Emilio Renzi and La ciudad ausente. It is argued here that Piglia views both Latin American and Argentinian history in a dystopian light. This interpretation is visually and narratively rooted in a tradition of dystopian novels and films, under analyzed in the studies about the Argentinian writer. With the recent publication of the diaries, and the posthumous appearance of books of lectures and interviews by Piglia, this interpretation line has become increasingly relevant.
\end{abstract}

\section{Keywords:}

Dystopia, contemporary Latin American literature, narration, power, science fiction, conspiracy, memory, surveillance.
Doctor en Literatura, profesor investigador , miembro del Grupo de Investigación en Filosofía, Hermenéutica y Narrativas de la Universidad EAFIT, Medellín - Colombia 
Este artículo emprende una lectura "retrospectiva" de La ciudad ausente, la novela que Ricardo Piglia publicó en 1992. La hipótesis seguida aquí es que la lectura en clave de distopía que se ha hecho de la novela ha sido hasta ahora insuficiente, por dos razones: la primera, que no hay aún estudios exhaustivos donde se caracterice efectivamente la distopía como género en relación con la literatura contemporánea en América Latina y, más específicamente, con la ficción posdictatorial; y la segunda, que solo con la reciente publicación de los diarios, conferencias y cursos de Piglia, hemos entendido el lugar central que en su trabajo ocupó la pregunta por la narración y el poder. De modo que reconstruir las fuentes para la elaboración de una obra en clave distópica resulta útil si se quiere entender cómo se procesan ideas, tradiciones y compromisos estéticos.

Así, una lectura de los tres tomos de Los diarios de Emilio Renzi (2015b, 2016c y 2017), cruzada con ensayos como "Teoría del complot" (2001, en línea) y colecciones como Crítica y ficción (1993a), ofrece una posibilidad inmejorable para entender la distopía como un camino hermenéutico de ricas posibilidades.

Que en la interpretación confluyan materiales de narración ficcional y no ficcional, ensayos literarios, textos críticos, conferencias y programas de cursos universitarios muestra por lo menos dos cosas: por un lado, la necesidad de que tópicos como el de la distopía sean entendidos a partir de procesos tanto creativos como analíticos; por otro, esa confluencia revela las múltiples facetas que una figura intelectual como la de Piglia suscita en la lectura informada, la crítica y la investigación. Y, si se quiere algo más, confirma la importancia que, para los estudios literarios, tiene el cotejo de materiales canónicos con textos "menores", antes impensados como fuentes para la crítica.

Leer La ciudad ausente (2010) como un lugar de cristalización de múltiples líneas de sentido, provenientes de fuentes textuales diversas, ayuda a una lectura más detallada y completa de problemas que distan de tener una manifestación única. En la imaginación distópica, con la que también pretendemos afiliar a Piglia a partir de la caracterización de sus gestos de apropiación de lo literario y lo cinematográfico, se halla una de las claves para abordar las siempre complejas relaciones entre poder y novela en América Latina. 


\section{Ricardo Piglia: la narración del complot y el complot de la narración}

El corpus ensayístico de Ricardo Piglia ha aumentado en el último tiempo con la publicación de varias entrevistas, conversaciones y cursos que ayudan a entender, de mejor manera, el conjunto de su obra. En tales textos, los planteamientos sobre las relaciones entre poder y narración tienen un lugar preponderante, no solo por su coherencia, sino porque además iluminan el quehacer narrativo del autor. Ensayo y ficción, como se sabe, solo son dos registros de una misma preocupación. Leer la ficción de Piglia desde sus propios ensayos, conferencias y diarios - e incluso desde sus actividades como profesor y conferencista - es una veta aún inexplorada. Sin duda, $\mathrm{La}$ ciudad ausente es una obra que podemos entender en la actualidad mucho mejor después de conocer las inquietudes que rondaban al autor a finales de los años ochenta, inquietudes que solo calibramos en su peso específico con la publicación reciente de textos ensayísticos y reflexivos.

La obra ensayística de Piglia constituye en sí misma un conjunto autosuficiente: Crítica y ficción (1986, 1993a), La Argentina en pedazos (1993b), Formas breves (1999), Diccionario de la novela de Macedonio Fernández (2000), El último lector (2005) y “Teoría del complot” (2001) son textos que podemos valorar por sus tesis, pero también por sus preocupaciones formales específicas. Son textos donde hay un especial laboratorio de ideas en proceso, y una manera, probablemente entre las más originales de la literatura latinoamericana, de combinar problemas argumentativos y narrativos.

Recientemente han aparecido otras obras. Se trata de escritos que si bien no tienen la condición de ensayos literarios, sí sirven, en tanto proyectos de información y de discusión, para entender de manera más integral algunos puntos de vista del autor. Son libros que reúnen conversaciones, intervenciones y conferencias que, a lo largo de los años, le sirvieron a Piglia de plataforma para la consideración de ideas que también iba desarrollando "creativamente": hablamos de libros como $\mathrm{La}$ forma inicial (2015a), Por un relato futuro (2015c), Las tres vanguardias (2016b) y Escritores norteamericanos (2016a).

Como se sabe, la relación entre el arte narrativo y el poder represivo del Estado es un tema recurrente en los textos argumentativos 
de Piglia. En su libro Crítica y ficción, publicado en 1986, y ampliado en 1993, las referencias al vínculo entre el Estado y la actividad narrativa aparecen varias veces, bajo la idea de que el discurso del poder adopta la forma de "una ficción criminal" (Piglia, 1993a, p. 11). El adjetivo "criminal" se refiere, por si hace falta decirlo, más que al tema, a los fines de la narración. Piglia señala que, en Argentina, los militares ficcionalizaron lo real "para borrar la opresión" (Piglia, 1993a, p. 11).

Como es de suponer, la idea de un Estado que se sirve de ficciones implica una oposición: la que frente a las ficciones propiamente oficiales marcan las narraciones alternas, es decir, las que circulan de manera clandestina. Esta idea, que merodea en Respiración artificial (1980) y llega a plenitud en La ciudad ausente, permite identificar al Estado como un agente centralizador de historias: "el Estado narra", puesto que ejercer el poder político es imponer una manera de contar la realidad (Piglia, 1993a, p. 35).

Ya trasladados al ámbito literario, se puede pensar con Piglia la dimensión utópica o distópica de los relatos solo si se admite la postulación de un modelo posible de sociedad. En última instancia, todo relato social se articula, desde el punto de vista de los géneros literarios, como utopía o distopía. "En el fondo los relatos sociales son alegóricos, siempre dicen otra cosa. Hablan de lo que está por venir, son un modo cifrado de anticipar el futuro y de construirlo" (Piglia, 1993a, pp. 37-38). Esa dimensión anticipatoria da a la narración literaria una facultad inmejorable para la advertencia. Dicho con palabras de García Canclini, la narración revela la especial disponibilidad del arte para manifestar un "estado de inminencia" (García Canclini, 2010, p. 12). ${ }^{1}$

Para Piglia, esta capacidad predictiva ocurre por condiciones históricas especiales:

Muchos escritores han sido capaces de percibir en el presente las líneas básicas de la realidad futura. Eso ha sucedido en general en momentos de gran condensación, cuando no es sólo un sujeto el que percibe los núcleos

1 "El arte es el lugar de la inminencia. Su atractivo procede, en parte, de que anuncia algo que puede suceder, promete el sentido o lo modifica con insinuaciones. No compromete fatalmente con hechos duros. Deja lo que dice en suspenso" (García Canclini, 2010, p. 12). 
de una sociedad, sino que hay grandes tensiones secretas que se hacen visibles y aparecen con nitidez los puntos de fuga del imaginario social (Piglia, 1993a, pp. 38-39).

Bajo esta perspectiva, el relato literario no es el único agente, ni las narraciones orales las únicas portadoras. El cine, la televisión, internet parecen haberle ofrecido a Piglia el referente material directo para entender la dinámica de los múltiples relatos sociales, resultan decisivos.

Sabemos, por los diarios de Piglia, que el cine desempeñó un papel muy importante en su formación y que, junto con la lectura intensa de los clásicos narrativos del siglo Xx, el cinematógrafo fue para él una especie de escuela. Está menos establecida la forma en que los modelos narrativos del cine y la televisión pasan a su ficción, y el modo en que sus problemas estéticos influyen en la literatura y la crítica que escribió. Quizás las implicaciones intermediales en la consideración de las narraciones frente al Estado es una tarea pendiente de realizarse en el trabajo interpretativo sobre Piglia. Aun así, esta primacía del medio masivo es para tener en cuenta y obliga a encontrar pistas en las referencias autobiográficas. Finalmente, en la historia literaria no hay distopía sin medios de información. Tema y agente, la narrativa, escrita o audiovisual, es parte integral de lo distópico.

Crítica y ficción revela la importancia que la televisión empezó a tener en el trabajo de Piglia. No solo por los temas que el autor encontraba en la programación, sino también por la misma lógica de ampliación y pluralización narrativa que, a su juicio, la desbordante oferta televisiva contemporánea ponía a disposición del espectador.

Descubrí la televisión en los Estados Unidos. Una de las temporadas que pasé en Princeton en el 1987 [...] me pasé como tres meses viendo televisión porque descubrí los canales de cable. Venía de Buenos Aires, donde había sólo tres o cuatro canales y me encontré aquí con un horizonte de setenta canales y en un sentido cuando empecé a entrar y salir de esos programas tuve una visión de lo que era una ciudad y esa experiencia está, me parece, muy ligada a La ciudad ausente, la ciudad es como una red de canales en los que uno puede entrar y salir, una red de historias superpuestas y paralelas, que funcionan todo el tiempo aunque uno no esté ahí (Piglia, 1993a, p. 222). 
La idea de que la sociedad está constituida por un conjunto de narraciones enfrentadas ofrece una de las claves constructivas de Respiración artificial y La ciudad ausente. Por esta razón, los ensayos y diarios donde el tema es la narración y el poder son, en nuestra lectura, cualificadores de una visión que no solo consiguió articulación en lo novelesco. La máquina de contar historias de La ciudad ausente, con la circulación clandestina de historias que buscan combatir la narración institucional, tiene por inspiración la máquina televisiva de narrar. ${ }^{2}$

En Formas breves, su recopilación de ensayos de 1999, conocido por las "Tesis sobre el cuento", donde aparece la célebre teoría de las dos historias, no encontramos mayores alusiones a las relaciones entre distopía, poder y narración. No obstante, allí se consigna la anécdota que dio origen a La ciudad ausente: una mujer que vendía flores a la salida de un club de boxeo, con la que a veces el autor conversaba. Contaba que había conocido a Macedonio Fernández y conservaba una grabadora con la voz de una mujer, presumiblemente Elena de Obieta, la esposa del escritor (Piglia, 1999, p. 46). Lo cierto es que no se dice que pueda ser la voz de su mujer, pero sí que se oye la voz del que parece ser Macedonio. La confluencia de estos dos problemas - un mundo policivo en el que las narraciones deben pelearse para abrirse paso en lo real y una mujer muerta confinada para su preservación en una máquina narradora - aventuran, desde esa definición, formulada media década después de publicada la novela, una inclusión de La ciudad ausente en el grupo de las distopías de ciencia ficción.

2 En el tercer tomo de los Los diarios de Emilio Renzi (Un día en la vida), encontramos un pasaje que demuestra el interés del autor por las narraciones como algo que ha desbordado la literatura (una obviedad, acaso) y por las transformaciones a las que el arte de narrar se ha visto sometido a causa de las aceleradas mutaciones económicas y tecnológicas. Dice Emilio Renzi, el narrador de los diarios, en una entrada sin fecha: "La narración social se ha desplazado de la novela al cine y luego del cine a las series y ahora está pasando de las series a facebook y a twitter y a las redes de internet. Lo que envejece y pierde vigencia queda suelto y más libre: cuando el público de la novela del siglo XIX se desplazó hacia el cine, fueron posibles las obras de Joyce, de Musil y de Proust. Cuando el cine es relegado como medio masivo por la televisión, los cineastas de Cahiers du Cinéma rescatan a los viejos artesanos de Hollywood como grandes artistas; ahora que la televisión comienza a ser masivamente sustituida por la web, se valoran las series como forma de arte. Pronto, con el avance de nuevas tecnologías, los blogs, los viejísimos e-mails y los mensajes de texto serán exhibidos en los museos. ¿Qué lógica es esta? Sólo se vuelve artístico lo que caduca y está 'atrasado"' (Piglia, 2017, p. 257). 
La ciudad ausente elabora motivos de la narrativa de anticipación, no porque presente desarrollos tecnológicos innovadores - los artefactos se limitan a unos autómatas y a una máquina en la que está confinado un mecanismo que narra-, sino por el tipo de estructura social que fabula. Y, si se quiere ser más específico, por la especulación con los posibles modos en que la información y la comunicación van a definir la coerción y la vigilancia en un futuro hipotético. Con la distopía, se vuelve sociológica la famosa pregunta asociada a la ciencia ficción: "QQué pasaría si X o Y?".

De hecho, sobre los motivos dobles de La ciudad ausente, el mismo autor había dicho en Crítica y ficción:

Digamos que he tratado de poner en relación cosas que a menudo parecen antagónicas, como puede ser cierta política conspirativa, cierta violencia clandestina y la obsesión por una mujer. En ese sentido el núcleo básico de la historia es muy sencillo: un hombre ha perdido a una mujer y en su lugar arma un complot (Piglia, 1993a, p. 137).

Esta conexión entre artefacto narrativo, complot de Estado y conjura de la pérdida amorosa, según va revelando Piglia en sus ensayos, fue la que soportó la orientación ideológica, la estructura poética y acaso el motivo lírico de la novela. Pese a su descentramiento estructural, a su organización rizomática y a su concepción fractal del espacio narrativo, La ciudad ausente reposa sobre una base problemática: las relaciones de pérdida y duelo como generadoras de una máquina de narrar que combate una conspiración "desde arriba". La historia, la memoria y la subjetividad solo tienen una garantía antropológica: la que ofrece un relato inscrito en la memoria genética de la humanidad, una memoria que solo puede revivir por obra de las máquinas.

La forma inicial, un libro recientemente publicado que recoge diversas conversaciones con Piglia en Princeton, ofrece pistas adicionales sobre la preocupación del escritor por las relaciones entre narración y poder, y específicamente por el motivo distópico implementado en La ciudad ausente.

Es cierto que La ciudad ausente es una novela que está hecha con esa hipótesis, de la existencia de un lugar donde se narran historias que el Estado trata de borrar. También eso está en la ciencia ficción (Piglia, 2015a, p. 150). 
Piglia se apresura a aclarar que no se trata de cualquier ciencia ficción, sino de la que a él le gusta, es decir, "la de Philip Dick o la de Ballard" (Piglia, 2015, p. 150). Esto no es gratuito, ya que, de Philip K. Dick, La ciudad ausente toma uno de sus motivos principales: la duda de un casi humano sobre su propia humanidad. ${ }^{3}$ Esta pregunta, habitual en las obras del escritor norteamericano, proviene del Frankenstein de Mary Wolstonecraft Shelley (1818), pero quizás se remonta hasta el Satán de Milton y llega hasta El hombre bicentenario de Isaac Asimov (1976) y los clones de Nunca me abandones de Kazuo Ishiguro (2005). Los protagonistas de las obras de Dick son replicantes que recuerdan a la máquina narradora del argentino, la cual se pregunta por su propia existencia. De J. G. Ballard, el escritor inglés autor de distopías como Rascacielos (1975) y La isla de cemento (1974), Piglia toma elementos cruciales para su novela, como la idea de una ciudad postindustrial donde las tecnologías, las drogas y la cultura del entretenimiento han instaurado una peligrosa confusión entre el paisaje interior y el espacio social.

La constante inquietud de Piglia por la actividad política de la narración conduce a una suerte de programa particular para la escritura de ficciones, que se mantiene casi inalterable hasta las conversaciones de La forma inicial. Un programa que, para Piglia, bajo la óptica de la responsabilidad política del escritor, reside en el lenguaje. Si tuviera alguna obligación política, la literatura debería confiscar las palabras y devolverlas modificadas, enrarecidas. "La literatura sería una crítica práctica de los usos sociales del lenguaje (pero no sería eso solo, claro)" (Piglia, 2015a, p. 184). El Estado es un constructor y propagador de ficciones (Piglia, 2015, p. 215), ante el cual se opone la literatura, ya que "está construyendo un universo antagónico a ese universo de ficciones estatales" (Piglia, 2015, p. 216). La reiteración de este tópico hace pensar en la relevancia que tuvo para Piglia el papel de la narración estatal a lo largo de los años.

Ahora bien, la idea de que la literatura ofrece narraciones antagónicas del Estado no es nueva, por supuesto, pues hace parte de la

3 El trabajo que más directamente ha hecho por esclarecer los vínculos de La ciudad ausente con la ciencia ficción es el de Berg (2000, p. 77), quien específicamente trae como referente a Philip K. Dick y las películas hechas a partir de sus relatos. 
vigorosa tradición de la distopía misma y de la ciencia ficción, en cuyas fuentes abreva La ciudad ausente. Orwell, Bradbury, Disch y el mismo Philip K. Dick confieren a la narración un papel político preponderante. El espacio de simbolización del lenguaje se convierte en uno de los lugares finales de la lucha. La ciudad ausente es una distopía doblemente literaria, de la misma manera en que lo son $\mathrm{Fa}$ renheit 451 de Bradbury (1953), Memorias encontradas en una bañera de Stanislaw Lem (1973) o El hombre en el castillo de Dick (1962). Con Farenheit 451, la novela de Piglia tiene en común el enclave protegido en el que los rebeldes custodian las narraciones y preservan el arte de narrar. Con las novelas de Lem y Dick, coincide en entender la narración como agente que define la realidad "oficial".

Ahora bien, donde quizás se halla la diferencia, o tal vez la gran singularidad de la novela de Piglia, es en la apropiación del museo, que garantiza el paso de la narración verbal al espacio intermedial. Un museo que, además, supera los lenguajes y medios expositivos tradicionales. Se trata de un espacio de exposición, no de consagración, sino de anulación, en el que la representación está presente, pero no a través de la imagen bidimensional o tridimensional clásica. El museo está dominado por la comparecencia de objetos y de instalaciones, que recrean elementos de las narraciones de la máquina, una máquina que por un gesto autorreferente acaba siendo parte del mismo museo.

La institución, bajo la personificación del museo, se convierte en un principio de domesticación de la narración y el arte. Hay que recordar que, en la novela, la máquina de Macedonio, a la que con Idelber Avelar podríamos definir como "combinación contrahegemónica de relatos en la postdictadura, preservación narrativa de una memoria en duelo en tiempos dominados por el olvido" (Avelar, 2000, p. 219), está en trámite de desactivación, pues se anuncia que va a ser llevada a un museo de provincia. Nada mal, por supuesto, para una distopía de los años noventa, década en que el pensamiento crítico, la práctica artística y el mismo ejercicio curatorial la emprendieron contra el museo como institución, como agente de la corrección política y la fosilización de las narraciones identitarias. Una década, además, en la que se leyó y comentó profusamente la obra 
de Michel Foucault, autor para el que la pregunta por las relaciones entre la práctica artística y el control social fue una preocupación fundamental.

\section{Distopía y complot}

El recelo respecto a la institución cultural tiene en la desconfianza en las narraciones oficiales su más importante faceta. Aspecto común a buena parte de las ficciones posdictatoriales, es fácil entender por qué la literatura es contranarración. Y quizás el ensayo donde más decididamente Piglia afronta el diálogo entre poder policivo y ficción es "Teoría del complot" (Piglia, 2001, en línea), uno de sus más originales esfuerzos interpretativos por aproximar conspiración y narración, y por reconstruir la historia de la tradición literaria argentina desde el imaginario distópico que ofrecen las pugnas políticas por la representación simbólica.

"Teoría del complot", conferencia del año 2001, permite entender con mucha claridad la base distópica que tienen las ideas de $\mathrm{Pi}$ glia sobre narración y poder. Un detalle que quizás no se puede pasar por alto es la fecha en que tuvo lugar la conferencia, impartida en Buenos Aires en julio del 2001, es decir, poco antes del gran atentado en Nueva York contra el World Trade Center, quizás el mayor hecho distópico de la historia reciente.

En el texto, Piglia (2001, en línea) dice que se propone discutir las formas del complot y sus relaciones con la novela, la vanguardia y la economía. De los tres tópicos, y para los fines de este artículo, el que más interesa en este momento es el primero, pues al discutir las entrañas conspirativas de la narración literaria, Piglia expone, en su conferencia-ensayo, su peculiar visión de las relaciones entre relato y poder y, más en detalle, algunas de las ideas elaboradas novelísticamente como distopía en La ciudad ausente una década atrás.

De hecho, varias afirmaciones de "Teoría del complot" incorporan motivos distópicos. Ya en Crítica y ficción, Piglia había hablado de este tema, de esta figura, anticipando una inesperada deriva literaria para el análisis del arte de la novela y el poder. De hecho, para Piglia, la clave de lo distópico signa la novela moderna y contemporánea: 
"Lo interesante es que las novelas han hecho del complot la clave de la interpretación de la sociedad” (Piglia, 1993a, p. 38).

La conferencia sigue a Walter Benjamin, quien a decir de Piglia había señalado en los años veinte la importancia de afrontar críticamente las relaciones entre información y acción social después de la Primera Guerra Mundial. La información es también un asunto de ocultación, concluye Piglia. La guerra se juega también en las palabras, en las narraciones, en lo que no se dice. La abundancia de datos produce una especie de ocultamiento, de secreto, al que es cada vez más difícil acceder. Según Piglia, hay una "presencia creciente de la idea de complot en las relaciones entre información y experiencia" (Piglia, 2001, en línea). Y es de suponer, ya como lectores contemporáneos de ese texto, que las redes sociales, las noticias falsas y la crisis del periodismo y la reportería vienen a incrementar esta dislocación entre lo que se puede realmente experimentar y lo que aparece en millones de representaciones.

Aunque haya mucha información disponible, prosigue Piglia (2001, en línea), existirá siempre algo que no sepamos, de manera que necesitamos una clave para acceder al sentido. Por eso, la novela construye, a partir de allí, su idea del relato social. La distopía, según tal razonamiento, vendría a ser una especie de narración criminal con base en la búsqueda de un dato oculto que pone en perspectiva el resto de la información. El Estado necesita de relatos, de agentes de control que den garantía para la lectura de lo social.

La cohabitación resultante, aunque podría parecer problemática desde el punto de vista político, resulta fecunda para el escritor de ficciones distópicas, ya que "Estado y complot vienen juntos. Los mecanismos del poder y del contrapoder se anudan" (Piglia, 2001, en línea). Y no porque lo segundo sea la contraparte de lo primero, por supuesto, sino porque lo segundo es el modelo genérico que adquiere la narración urdida por el primero. Las distopías han mostrado que la pugna entre el Estado y las formaciones sociales clandestinas puede tener el aspecto de una lucha por las representaciones y la escritura de la historia.

Para Piglia, como ya decíamos, el complot ofrece una posibilidad de lectura de la tradición literaria argentina. Como en muchos otros 
temas de análisis literario e historia en que incursionó, el escritor argentino se comporta como un crítico ejemplar, pues evade el lugar común, elige un ángulo inusitado y saca conclusiones iluminadoras. Algunas ideas aportadas por esta singular aproximación a los clásicos argentinos resultan elocuentes y muestran la presencia del imaginario distópico en el pensamiento crítico del Piglia ensayista, tanto o aun más que en las ficciones del Piglia novelista.

Dice Piglia que muchos escritores argentinos, por ejemplo, Roberto Arlt, establecen "su noción de ficción" alrededor de la conspiración. "Sus textos narran la construcción de un complot y, al decirnos cómo se maquina un complot, nos cuentan cómo se construye una ficción" (Piglia, 2001, en línea). Está por descontado que, como dice Arlt, haya que "hacer un complot contra el complot", una frase que Piglia usa como epígrafe de su conferencia. El reconocimiento termina siendo doble, entonces: por un lado, aparece la dimensión narrativa de la conjura y, por otro, el complot como tema principal de las narraciones.

El complot se entiende, de esta manera, como una especie de género narrativo, como una forma estetizada de la conspiración, como una incorporación de los vectores del funcionamiento del lenguaje en la política en el universo del arte.

A menudo, el relato mismo de un complot forma parte del complot y tenemos así una relación concreta entre narración y amenaza. De hecho, podemos ver el complot como una ficción potencial, una intriga que se trama y circula y cuya realidad está siempre en duda (Piglia, 2001, en línea).

El carácter siempre probable de la narración distópica, la identidad ficcional de la conspiración factible, define el estatus de la narración en la sociedad contemporánea, ya que en un mundo confuso, donde proliferan informaciones falsas, donde la economía se mueve por resortes que ignoramos, la narración-complot funciona como desactivadora de las ficciones imperantes.

Es obvio que esto puede dejar a la narración en un lugar subordinado, pues se desactivan sus principales poderes autónomos. Sin embargo, el relato conserva una capacidad fundadora. ${ }^{4}$ La narración

4 Avelar lo dice de manera más contundente: "Ya no se trata tanto de narrar los hechos 
puede siempre actualizarse, y en tal sentido asegurar su eficacia social. El periodismo de investigación serio, el documental, la crítica y el ensayo caben dentro de esa categoría de narraciones alternas "necesarias". Ahora, esta idea del complot como ficción en potencia se vuelve una oportunidad para generar espacios inéditos de subjetivación.

En "Teoría del complot", el examen de Piglia incluye a Arlt, con el que introduce el tema, y prosigue con Borges y Macedonio, autor este último que es el personaje conspirativo principal de La ciudad ausente. En "Tlön, Uqbar, Orbis Tertius", el cuento de Borges, Piglia encuentra una de las formas literarias del complot, aquella que pone de presente la intromisión perturbadora de la ficción en lo real. Dice:

Un texto como este, que trabaja el complot como base, permite percibir la presencia de la ficción en lo real, la ficción en la política, la manipulación de la creencia, las historias que se vuelven reales (Piglia, 2001, en línea).

Tlön es un modelo de legibilidad, pero también de ocultamiento. Y en "Tema del traidor y del héroe", otro cuento de Borges del que se ocupa, complot y acto de narrar se traslapan: "La relación entre complot y escritura de la historia está en el centro de la trama. (Habría mucho que decir sobre esto en la historia argentina, y no sólo en la historia argentina)" (Piglia, 2001, en línea).

En "La lotería de babilonia", texto de Borges en el que Piglia se detiene, se da una de las apariciones más características del Estado en tanto instancia reguladora de las relaciones sociales. Según Piglia, esta idea — presente en el que, a su juicio, es uno de los cuentos más políticos de Borges - proviene de La República, texto que vendría a ser el "fundador de lo que entendemos como la construcción de la realidad desde el Estado" (Piglia, 2001, en línea). Tanto en el texto de Platón como en el de Borges, los gobernantes juegan con el destino de la gente y regulan el acceso a esa realidad, para que cuando surja el descontento, el pueblo le eche la culpa a la suerte. Para Piglia (2001, en línea), desde La República, el Estado siempre hace trampa.

reales como de narrar las ruinas y restos de la historia, como quien lanza un desafío al porvenir, una invitación a un relato futuro. Si nos roban la máquina de historias macedoniana [...] también los muertos estarán en peligro" (2000, p. 219). 
Y es necesario que esa trampa esté oculta. La lectura de Platón a través de Borges no es gratuita, pues reconoce en uno de los textos fundacionales de la narración utópica, La República de Platón, la fuente principal para entender las relaciones problemáticas entre Estado y narración. Finalmente, la narración es importante en la trampa urdida por el Estado, porque ella le permite a este jugar con el sistema de causalidad y hacer una representación interesada de la temporalidad. La hermenéutica ha recordado el sustrato ideológico que gravita sobre esta capacidad del relato para construir las representaciones oficiales del mundo.

Los años noventa son, además, una década en la que el museo se convierte en un lugar de fuertes luchas por la representación y la narración social. Todo museo, y más aun si es un museo nacional, empieza a recibir preguntas críticas sobre el marco ideológico que define su narración. Recordemos que, recientemente, en América Latina se han dado polémicas en torno a quién narra en los museos de la memoria o del posconflicto. La misma derecha ha incorporado a su instrumental discursivo la idea, que se creía de izquierda, de que quien narra pone en cierto modo las condiciones para afrontar lo real.

Por tanto, en el análisis de Piglia importan las cuestiones políticas y las cuestiones estéticas. Todavía en "Teoría del complot", al hablar de Macedonio, Piglia discute aspectos del proceso creativo de una novela, pero también de una forma de acción política del autor. Dice Piglia sobre Museo de la novela de la eterna, la obra experimental de Macedonio:

El nudo ficcional es la construcción de un complot y, a la vez, ese complot se superpone con la escritura de una novela. Las múltiples estrategias de lo novelístico que circulan por el texto tienden a funcionar como una conjura destinada a producir efectos en la realidad y a construir un conjunto específico de lectores que actuarán como conjurados ellos mismos. Así, la novela construye a sus lectores como cómplices de una conjura secreta (Piglia, 2001, en línea).

Piglia está hablando de las propias actividades anarquistas de Macedonio, así como de su aspiración a la Presidencia de la República, usada como una suerte de acción anarquista. La metáfora del nudo blanco es neurológica, y Piglia la aprovecha para ir, por la vía 
que abrió Philip K. Dick, al corazón del problema de la memoria, nutrido de narraciones personales y narraciones colectivas. El Piglia teórico social de la narración se junta con el crítico e historiador de la literatura argentina y con el novelista, para producir una obra donde la lucha por el poder procede del juego por la custodia y el mantenimiento de las narraciones.

$Y$ es que si bien la lectura de la historia literaria argentina resulta interesante en la conferencia del 2001, lo es más el que esa lectura se haga en clave de complot. ${ }^{5}$ Piglia parece advertir una conexión profunda entre el poder del Estado y la concepción de lo trágico, que en la Modernidad se muda de la tragedia aristotélica a la novela, género burgués, de las tensiones sociales. Que el complot del Estado reemplace al destino explica la omnipresencia de la conjura en la novela contemporánea.

En la novela como género, el complot ha sustituido la noción trágica de destino: ciertas fuerzas ocultas definen el mundo social y el sujeto es un instrumento de esas fuerzas que no comprende. La novela ha hecho entrar la política en la ficción bajo la forma del complot. La diferencia entre tragedia y novela parece estar ligada a un cambio de lugar de la noción de fatalidad: el destino es vivido bajo la forma de un complot. Ya no son los dioses los que deciden la suerte, son fuerzas oscuras las que construyen maquinaciones que definen el funcionamiento secreto de lo real. Los oráculos han cambiado de lugar, es la trama múltiple de la información, las versiones y contraversiones de la vida pública, el lugar visible y denso donde el sujeto lee cotidianamente la cifra de un destino que no alcanza a comprender (Piglia, 2001, en línea).

\section{Emilio Renzi: la memoria de la vigilancia y la vigilancia de la memoria}

Ahora bien, si los ensayos, textos críticos, conversaciones y conferencias de Piglia permiten entender las relaciones del poder del Estado con la narración y, más específicamente, con el género distópico, algo parecido podemos decir de la trilogía de Los diarios de Emilio Renzi. Estos escritos ofrecen no solo un logro literario en sí mismo, sino también la posibilidad de enmarcar más claramente

5 Una de las grandes ausencias en la reflexión de Piglia es quizás la de Bioy Casares, un autor que tuvo un particular interés por este tema. 
obras individuales como La invasión (1967) o Respiración artificial en el proyecto literario de Piglia, del cual Los diarios vienen a ser su base. Si bien estos últimos no cubren la época en que se escribió $\mathrm{La}$ ciudad ausente y no hay muchas alusiones a esta obra, aparecen allí referencias a lo distópico y al concepto de ciudad, que habían sido expuestas en "Teoría del complot", discutidas en Crítica y ficción y ficcionalizadas en La ciudad ausente.

Los tres tomos nos muestran la evolución de las ideas sobre narración e historia, narración y poder, y narración y vigilancia. Unos vínculos que, como es de suponer, Piglia pudo atestiguar durante sus años de formación en Argentina. En esos casos, el problema se piensa no solo como una posibilidad para la ficción, sino, y sobre todo, como un trasunto de la vida cotidiana del intelectual en la Argentina. Cuando los años se tornan difíciles, cuando el totalitarismo empieza a permear las esferas de la vida argentina, lo distópico y lo policial se convierten en una clave de lectura para comprender los años de Ricardo Emilio Piglia Renzi. Lo narrado en los diarios tiene gran semejanza con las huidas de La ciudad ausente, con su clima opresivo, con la promesa de que la escritura, la lectura y la discusión son la única alternativa ante las liquidaciones de la brutalidad militar.

En Un día en la vida, entrega final de los diarios, Renzi nos pone repetidamente de cara con la imaginería utópica. En algún momento, a propósito de la dictadura, Piglia parece confiar en el carácter sanador de la narración:

El peligro, el terror, la maldición de una realidad sin salida, se transforma muchas veces en relatos, pequeñas historias que circulan en medio de la noche para contar imaginariamente la experiencia vivida de esos días oscuros y poder soportarlos y sobrevivir. La narración alivia la pesadilla de la historia (Piglia, 2017, p. 13).

¿A quién alivia? ¿A los que la padecen? ¿O alivia a la historia misma de sus malos sueños? En una anotación fechada el 25 de agosto de 1982, también incluida en el tercer tomo de los diarios, leemos: “decido que mi lugar político es la utopía” (Piglia, 2017, p. 157).

También en la tercera entrega de los diarios, la imaginación distópica se transfiere como gesto autorreflexivo. Hay un largo pasaje ( $\mathrm{Pi}$ glia, 2017, pp. 234-240) en el que el autor transcribe una especie de informe arqueológico publicado en el siglo XXIII o XXIV, y donde se hace 
una reseña de los mismos Los diarios de Emilio Renzi. Es algo así como la transcripción de un sueño, con el que se da un informe en clave distópica de Los diarios de Emilio Renzi. Esta reseña imaginaria futura, en la que el autor parece no entender algunas de las cosas que definen la vida del siglo Xx, representa un ejercicio metaficcional y, a la vez, una puesta en abismo del presente entendido como futuro y vivido como pasado.

Estos pasajes pertenecen a un momento en que Piglia ha decidido no seguir con la cronología de años, tal como había sido presentada en los dos tomos anteriores. De manera que ofrecen anotaciones que guardan una relación metonímica con la historia general. Son biografemas, pedazos de vida narrada. Son, como el mismo título del tomo lo indica, Un día en la vida, nombre extractado, como se sabe, de una canción de los Beatles.

Solo hay una anotación en los diarios sobre La ciudad ausente, obra a la que Renzi vincula con una utopía dada por la creación de un mundo en miniatura para recuperarse de la pérdida de una mujer (Piglia, 2017, p. 188). No se puede dejar de anotar que la novela aparece, bajo esta síntesis, como directa heredera de un grupo de obras que se preocupan por la creación de inteligencia artificial: $\mathrm{La}$ invención de Morel de Bioy Casares (1940), La Eva Futura de Auguste Villers de L'isle Adam (1886) y, sobre todo, El castillo de los Cárpatos, de Julio Verne (1892), en la que se busca conservar a la mujer muerta - una cantante de ópera- a través de la preservación de la voz. Motivo auditivo este que, como ya se ha dicho, marca la invención de la trama de la novela de Piglia.

Ahora bien, a falta de pistas precisas en Los diarios sobre lo que Piglia estaba considerando cuando escribió La ciudad ausente, y sobre lo que ocurre después de la publicación de Respiración artificial en pleno auge de la dictadura, que queda un poco en la sombra, son de suma utilidad los testimonios de amigos y colegas de Piglia, que fueron testigos de su preocupación por el tema distópico.

En su recuento de los años de Piglia en la Universidad de Princeton, Arcadio Díaz Quiñones señala las inquietudes profesorales de Piglia por la época en que La ciudad ausente era un proyecto en pleno desarrollo: 
En la primavera de 1989 ofreció un curso sobre "Novela y dictadura: el poder autoritario en la tradición literaria" que podríamos ver hoy como un documento de su propia biografía. En él proponía analizar "las formas que adquiere la narración en un contexto de represión política", concretamente en la Argentina de 1976 a 1982. En la descripción se anunciaba así: "se estudiarán los signos de la política autoritaria en el lenguaje y en la vida cotidiana de la época" y asimismo "los usos de la ficción y de la no-ficción en la representación literaria". En las primeras sesiones se leyeron textos de Borges, Arlt y Lugones, y después se pasó al tema de "El estado autoritario y la guerra sucia" y "El ejército como fuerza clandestina", para lo cual servía el texto más atravesado por el trauma, el Nunca más de la Comisión Sábato. Otra sesión estuvo dedicada a Humberto Constantini y también a Manuel Puig, cuyos libros habían sido prohibidos, seguramente por las referencias a la tortura, pero también por la sexualidad diferente que desplegaban. El tema era el exilio: "La patria perdida como tradición de los intelectuales", con fragmentos de Pubis angelical de Puig, y "En la noche", de Constantini. Es uno de los pocos cursos en los que Piglia se nombra a sí mismo como escritor e incluye sus propios textos: fragmentos de Respiración artificial, en la sesión dedicada a "las formas cotidianas del terror político". Era el testimonio de un sobreviviente, alguien que sabía, como el Walter Benjamin de las Tesis de filosofía de la historia, que ni siquiera los muertos estarán a salvo (Díaz Quiñones, 2015, pp. 20-21, en línea).

Estos testimonios revelan una preocupación específica que quizás el tercer tomo de los diarios no alcanza a mostrar de manera tan precisa. Aun así, es de resaltar el modo en que concluyen Los diarios de Emilio Renzi: aquellos pasajes sobrecogedores que no sabemos muy bien cómo fueron escritos. En los medios se ha difundido que Piglia ordenó y escribió la última parte de sus diarios con una condición física cada vez más precaria, ayudado por un software para comunicarse. Ya la publicación de los diarios era un proyecto en curso, como se pone de manifiesto en el documental que habían realizado Gema Juarez Allen y Andrés di Tella (2015).

Que en la propia vida de Piglia reaparezca el tema de la máquina narradora, inmóvil, no deja de ser impactante. La tecnología, de la que el Piglia autor debe servirse para completar sus diarios, aparece como cualificador de una extrema conciencia corporal. Ya las tecnologías de información y comunicación habían aparecido en varios 
de sus ensayos y conversaciones, como, por ejemplo, aquellos incluidos en las charlas en Princeton, en los que habla del cambio que las tecnologías han introducido en los hábitos narrativos. Pero, por primera vez, después de La ciudad ausente, la tecnología se ve ligada a una condición a la que podríamos llamar "poshumana". Es como si el tema de la máquina narradora de La ciudad ausente, solitaria y abandonada, sometida a la reflexión sobre su propio ser, hubiera adquirido, por juegos del destino, una dimensión autobiográfica.

Con los inicios de la enfermedad, la narración de Un día en la vida se torna triste y lacónica:

\section{Martes}

Morir es difícil, algo me sucede, no es una enfermedad, es un estado progresivo que altera mis movimientos. Esto no anda. Empezó en septiembre del año pasado, no podía abrochar los botones de una camisa blanca (Piglia, 2017, p. 293).

Sábado 5

Mi vida depende ahora de la mano derecha, la izquierda empezó a fallar en septiembre después de que terminé el programa de televisión sobre Borges. Me sucedió en ese momento, pero no a causa de eso. Los médicos no saben a qué se debe. El primer síntoma fue que no podía hacer movimientos finos, los dedos ya no me obedecían (Piglia, 2017, p. 293).

No es gratuito que las últimas secciones de los Diarios, seguramente escritas cuando Piglia estaba inmovilizado por la esclerosis lateral amiotrófica, que había empezado a aquejarlo desde el año 2013, tuvieran por título expresiones como "La marea baja", "La isla", "Un día perfecto" y "La caída". Todas ellas, no hace falta explicarlo, son frases que afirman el imaginario utópico y distópico. Sístole y diástole de una vida dedicada a las letras, a la confianza en la narración, pero que ya en ese momento se apagaba.

La última entrada del diario, que significativamente se data el lunes, primer día de la semana, ofrece pensamientos que hacen pensar en la máquina de La ciudad ausente extinguiéndose lentamente en la colonia: 


\section{Lunes}

La mano derecha está pesada e indócil pero puedo escribir. Cuando ya no pueda...

Siento que crece en el cuerpo un hormiguero, una batea. Quiero estar seguro antes de anotarlo. Escrupuloso hasta el fin.

Siempre quise ser sólo el hombre que escribe.

Me he refugiado en la mente, en el lenguaje y en el porvenir. No puedo ya vestirme solo, así que me he hecho confeccionar una capa, o mejor, una túnica que me cubre el cuerpo cómodamente, con dos lazos para atarla. Tengo dos atuendos; mientras uno se lava, uso el otro, son de lino color azul, no necesito nada más.

La enfermera meretriz puede entrar en el cuarto a cualquier hora, mientras yo, entre los pliegues de la cama, miro la ciudad por la ventana.

El papagayo en una jaula.

La silla de ruedas, el andar mecánico, el cuerpo metálico.

La enfermedad como garantía de lucidez extrema.

Una dolencia pasajera.

Para no desesperar, he decidido grabar algunos mensajes en voz alta en una diminuta grabadora digital que reposa en el bolsillo alto de mi capa, ¿o de mi caparazón?

Si uno puede usar su cuerpo, lo que dice no importa.

El genio es la invalidez (Piglia, 2017, pp. 293-294).

\section{La ciudad ausente: la maquinación narrada y la narración maquinada}

La idea de una experiencia corporal alterada por obra de la tecnología, de una conciencia que se transforma por la presión que sobre ella ejerce el poder del Estado a través de las narraciones, de la pesadilla de la historia contra la que hay que luchar, es una de las puertas de entrada a la distopía. El lector es testigo del eclipse de la máquina de La ciudad ausente y de Emilio Renzi. Dos narradores, pero también dos conciencias, o más bien dos caras de la misma conciencia, en el acto de narrar. La pesadilla de la historia, que en el caso de la máquina consiste quizás en quedar varada en la orilla del relato principal, el que la abarca y de alguna manera la quiere paralizar, aparece 
también en los diarios, donde la inmovilidad del cuerpo narrador deviene poderosa alegoría: la que muestra un acto narrativo individual, detenido ante la fuerza de la historia.

Pero aún hay mucho más, pues La ciudad ausente es una obra a la que se puede calificar como distópica por muchas otras razones: unas de filiación intertextual, otras de estructura o forma, y algunas más relacionadas con unos motivos que adquieren particular relevancia durante el siglo XX, un siglo que vio, además del ascenso de los totalitarismos, un desarrollo tecnológico y unas condiciones económicas y sociales enteramente nuevas. Si la dictadura en varios países de América Latina era la máquina oficial de narrar, el sistema bipolar hacía lo propio en tiempos de la Guerra Fría.

La ciudad ausente, como ya se ha dicho, se estructura alrededor de una historia matriz: la de Macedonio Fernández, conocido después en la novela como Mac, quien recibe ayuda de un ingeniero de Europa Oriental que le propone confinar a su esposa Elena, recientemente fallecida, a una máquina. Esta historia, parcialmente develada por Junior, un periodista de origen inglés que obtiene de modo clandestino datos sobre la historia de la máquina, así como copias piratas de sus historias, permite descubrir su funcionamiento. Luego de una excursión por el Museo donde la máquina está confinada, un lugar en el que se recrean algunas de las historias, Junior accede al mito fundacional de una colonia disidente a la que viaja al final. Allí reina una utopía lingüística en la que las lenguas cambian, salvo el libro sagrado, El Libro: el Finnegans Wake.

El diccionario de la Real Academia Española (RAE) incluyó recientemente en sus páginas el término "distopía". Antes, quizás, era corriente el uso de "utopía pesimista", una voz compuesta que significa casi lo mismo, pero que no era tal vez tan contundente ni tan específica. La definición es la siguiente: "Del lat. mod. dystopia, y este del gr. $\delta v \sigma$ - dys- 'dis-2' y utopia 'utopía'. 2. f. Representación ficticia de una sociedad futura de características negativas causantes de la alienación humana" (RAE, en línea). ${ }^{6}$ La distopía viene a ser una suerte

6 Obsérvese que la presencia de la alienación y la orientación negativa marcan la identificación hecha por el diccionario. 
de utopía al revés, la inversión radical de sus principios centrales: el orden y el rigor. Como en el grabado de Goya, la distopía es el sueño de la utopía que se vuelve monstruo.

Si bien la relación entre La ciudad ausente y la distopía está más o menos establecida, las referencias a los motivos específicamente vinculados con la utopía pesimista han sido poco analizados. Además de la lectura que se puede hacer a partir del binomio narración/ poder y de la lectura cruzada de la novela, los diarios y los ensayos —objetivo central de este artículo—, se pueden advertir una serie de motivos que aparecen en la tradición distópica y que Piglia reelaboró en su novela de 1992. Los enumeramos brevemente con el fin de confirmar, desde el interior de la misma novela, una presunción que los textos críticos y diarísticos dejan ahora entrever con mayor claridad: el acto de narrar, del narrar distópico, es el que permite escapar de la pesadilla de la historia, de la pesadilla de una narración hegemónica y alienante.

Empecemos por lo último que nos dejan Los diarios de Emilio Renzi: un cuerpo dotado de conciencia narrativa, pero que duda de los límites de la percepción y de los límites de lo humano. En La ciudad ausente, las alusiones a la interacción compleja entre máquina y cuerpo recuerdan una línea importante de la tradición distópica que anida en la ciencia ficción, y de la cual la máquina narradora de Macedonio y Russo, el ingeniero, es heredera. Empieza con el Frankenstein de Mary Wolstonecraft Shelley, sigue con La Eva futura de Villers de Lisle Adam, pasa a La invención de Morel de Bioy Casares y culmina con los replicantes de Philip K. Dick o los clones de C. J. Cherryh y Kazuo Ishiguro. Como en Metrópolis, la novela de Thea von Harbou (1926) llevada al cine por Fritz Lang (Pommer y Lang, 1927), reaparece el motivo de la autómata, robot o replicante. La pregunta por la identidad personal, por los límites de lo humano y lo poshumano se vuelven el centro de la pregunta existencial.

Por otro lado, y como ya se dijo, la sociedad retratada en la distopía está dominada por la vigilancia y el control policivo ejercido por el Estado. No hay acaso tema más característico del género. De Un mundo feliz de Aldous Huxley (1932) a Farenheit 451 de Ray Bradbury, pasando por 1984 de Orwell (1949), el control es uno de 
los elementos infaltables. Además, la Buenos Aires de La ciudad ausente es un lugar donde la represión del Gobierno, imaginaria prolongación de la dictadura militar, se extiende por la vida pública y la vida privada mediante un mecanismo propiamente narrativo.

Piglia da un sello particular a la distopía, poniendo en el centro una preocupación por la narración y por el lenguaje. A diferencia de la ciencia ficción clásica, la novela de Piglia no va a la búsqueda de una nueva y sorprendente realidad poblada de artefactos asombrosos, sino que muestra una imagen desviada del futuro, en la que se advierten las peligrosas derivas del mundo presente, la inminencia de la pesadilla y el terror.

El lenguaje se define como lugar del control, pero también como espacio para la revolución. Si bien el marco narrativo creado por el poder estatal parece incontestable, el hecho de que ese marco haya sido hecho con un instrumento plástico, acomodable, pasible de metáfora, en él está la posibilidad de la revuelta. En su primera manifestación, la novela de Piglia revela las raíces orwellianas de su concepción, pero se aparta de él por el hecho de que las voces narrativas se pluralizan. La neolengua, incontestable en 1984, se torna atacable en La ciudad ausente. Las consignas reivindicativas de Metrópolis se recrean en los libros custodiados por los rebeldes de Farenheit 451 o en el libro sagrado defendido por el protagonista de la película Soy leyenda. La neolengua adquiere, en La ciudad ausente, el carácter de un dispositivo de custodia narrativa que controla hasta cierto punto, pero que no puede definir del todo lo real. En la colonia a la que se llega remontando el río, vive una sociedad que venera el Finnegans Wake como obra sagrada y que vive el lenguaje como el único lugar posible de escapatoria.

Ahora bien, los asuntos más plenamente referenciales de la distopía aparecen de manera también desviada en la novela de Piglia, de modo que la ciencia ficción, el hard boiled y el cyberpunk son un intertexto enrarecido, pues sufren una apropiación periférica, provinciana, descentrada. Recordando a Avelar, son referencias culturales que la novela afronta como ruinas. Por tal razón, La ciudad ausente tiene respecto del pasado y del lugar donde este se conserva, el museo, una condición alegórica. El futuro es un lugar de ubicación incierta 
y se representa, de alguna manera, a partir de la incertidumbre que produce el progreso tecnológico. La trama se mueve en una especie de caos historiográfico, pues se trata de un mundo atravesado por un pasado traumático que se reactualiza solo como lenguaje. Los futuros avanzados y relucientes de las películas más o menos tópicas que juegan con el temor a la catástrofe ceden el paso a visiones que pueden ser retrógradas o anacrónicas. Con tecnologías pasmosas, pueden convivir la miseria y el atraso, o formas casi premodernas del urbanismo. Una ciudad que, como la de Blade Runner (Lauzirika, Deeley y Scott, 1982), parece, no del futuro, sino del pasado, oscura, laberíntica. Como muchas otras distopías posteriores, el futuro recicla el pasado y muchas cosas que en él aparecen es como si nos llevaran a otra época. La ciudad ausente es, además de intempestiva en sus aspectos referenciales, una distopía provinciana. Cohabitan en ella los costumbrismos más reconocibles, así como una especie de exaltación de lo periférico y lo rural.

Y es este, precisamente, uno de los puntos que nos lleva a los referentes literarios que menos se han señalado. La ciudad ausente construye una atmósfera que recuerda, por un lado, a la novela negra, aspecto ya señalado por la crítica; y, por otro, al cyberpunk y la narrativa distópica. Por atmósfera entendemos un conjunto de elementos de orden temático y constructivo que, en el caso de Pigia, vienen tanto de la literatura como del cine. La novela hace pensar en novelas como Neuromancer de William Gibson (1984), mientras que la estructura policial muestra a investigadores y criminales descentrados, vagando por laberintos del mercado negro, en medio de drogas y espacios que no otorgan ninguna posibilidad de redención.

El otro asunto es espacial. La isla es el símbolo dominante, tanto de la utopía, como de la distopía. Desde Moro hasta las reservas de Farenheit 451 y Un mundo feliz, o las naves espaciales y los planetas de la ciencia ficción, el espacio separado, el espacio-otro, es constitutivo. Para la utopía y para la distopía, resulta necesaria esta suerte de metonimia en que se convierte la isla. Toda distopía se revela, entonces, como una construcción insular, por lo menos en dos sentidos, uno figurado y otro referencial. En la novela de Piglia, por un lado, se presenta una sociedad que parece haberse aislado para ser 
representada y, por otro, en la parte final, el protagonista va precisamente a una isla en la que se hallan las huellas de la actividad asociada a la creación de la máquina. La sociedad otra, la sociedad alternativa, adquiere en La ciudad ausente cara de utopía pirata, "zona temporalmente autónoma”, como llamó Hakim Bey a su modelo de sociedad futura en su texto homólogo, también publicado en 1992 (Bey, 1992, en línea).

La historia — esta vez bajo la figura del museo- aparece como un lugar de lucha por las representaciones-narraciones. Si en Orwell, Bradbury, Huxley y Dick la representación distorsionada o la anulación misma de las representaciones del pasado es fundamental, la novela de Piglia nos da una especie de cancelación de la narrativa histórica misma, de suerte que la proliferación de historias —oficiales o clandestinas - mina la posibilidad de una ficción dominante. Por ello, aunque el poder militar tiene el dominio de la propaganda, la novela descentra las estrategias de control en la gramática y muestra desde la anarquía la superposición de mundos narrativos.

Alrededor del imaginario típicamente distópico de una ciudad sin centro, con sus coordenadas históricas extraviadas, con unos actores del poder que carecen de rostro, pero que se nos muestran en sus efectos, el autor argentino construye su imagen de la urbe. Piglia articula varios mitos y ficciones alrededor de la fundación mítica de Buenos Aires. Como otras novelas negras o distópicas, La ciudad ausente busca hacer una cartografía urbana, levantar la trama literaria, histórica y topográfica que subyace a la ciudad. La inspira, como el mismo Piglia dijo, el símbolo de los canales de televisión, presentados metafóricamente como líneas narrativas donde pueden rastrearse posibles órdenes de lo real.

\section{Conclusión}

Considerar un tema como la distopía en relación con la política y la narración pone de presente la necesidad de asumir ensayo, crítica, ficción y narración como componentes de un mismo proyecto intelectual y literario. Escritores como Piglia introducen en su proceso una especial gravitación hacia el ensayo en tanto discurso múltiple y polifacético. De ahí que la exposición y la argumentación sean caras 
del mismo problema que nutre a novelas y cuentos. Una vez entran en juego los diarios, el asunto se cualifica aún más, pues este último registro adquiere el carácter de una matriz. Laboratorio de creación, pero también impulso que define la performatividad de todo acto literario, la escritura en Los diarios de Emilio Renzi forma, respecto del corpus de Piglia, una suerte de más allá de la escritura.

De ahí que estemos ante un problema genológico y filológico. Se revela la importancia de los textos de reciente publicación, los cuales, a pesar de su estatuto genérico y literario difuso, ayudan a iluminar en retrospectiva algunos problemas vistos en textos canónicos como La ciudad ausente. Esto ocurre, por ejemplo, con el análisis político de la narración y, más específicamente, con el imaginario distópico, que desde Respiración artificial va a ser permanente en todos los textos del escritor.

La ciudad ausente es una obra que se comprende mejor si se cruza con las ideas sobre poder y narración, vigilancia y complot, que atraviesan la totalidad de la obra ensayística y diarística de Piglia. Se ven más claramente las apropiaciones de la tradición literaria argentina y universal, entre ellas la de una narración que siempre está en relación problemática con el poder y que tematiza la narración social como conspiración.

Si bien la distopía se ha invocado como referencia de La ciudad ausente en reseñas y notas periodísticas desde su mismo momento de publicación, la relación entre la novela y los motivos distópicos del cine y la novela ha sido muy poco estudiada. Este vínculo, que se define como núcleo de problemas para la consideración contemporánea de las ficciones que tratan del poder, se manifiesta en la novela de Piglia mediante la apropiación de varios motivos "clásicos", que encontraron su principal elaboración en distopías canónicas como Un mundo feliz, 1984 o Farenheit 451. Una lectura de lo distópico en América Latina, en diálogo con la distopía moderna, debe considerar a Piglia como uno de sus practicantes sino, además, como uno de sus teóricos más importantes. A la larga, la novela experimental y el ensayo crítico son los principales agentes para escapar de una pesadilla que también usa las formas narrativas y argumentativas para instaurar las formas constantes de la opresión 【 


\section{Referencias}

Asimov, I. (1976). The Bicentennial Man and other Stories. New York: Doubleday.

Avelar, I. (2000). Alegorías de lo apócrifo: Ricardo Piglia, duelo y traducción. En J. Fornet (Ed.), Ricardo Piglia (pp. 209-233). Bogotá: Fondo Editorial Casa de las Américas, Instituto Caro y Cuervo.

Ballard, J. (1974). Concrete Island. London: Jonathan Cape.

Ballard, J. (1975). High-rise. London: Jonathan Cape.

Berg, E. (2000). El relato ausente (sobre la poética de Ricardo Piglia). En J. Fornet (Ed.), Ricardo Piglia (pp. 65-85). Bogotá: Fondo Editorial Casa de las Américas, Instituto Caro y Cuervo.

Bey, H. (1992). La zona temporalmente autónoma (TAz). Recuperado de http://www.merzmail. net/zona.htm

Bioy Casares, A. (1940). La invención de Morel. Buenos Aires: Losada.

Bradbury, R. (1953). Farenheit 451. New York: Ballantine Books.

Díaz Quiñones, A. (2015). Ricardo Piglia. Los años de Princeton. Recuperado de http:// www.80grados.net/wp-content/uploads/Ricardo\%20Piglia-Princeton.pdf

Dick, P. (1962). The man in the High Castle. New York: Putnam.

García Canclini, N. (2010) El mundo sin relato. Antropología y estética de la inminencia. Buenos Aires: Katz.

Gibson, W. (1984). Neuromancer. New York: Ace.

Huxley, A. (1932). Brave New World. London: Chatto \& Windus.

Ishiguro, K. (2005). Never let me go. London: Faber \& Faber.

Juarez Allen, G. (Productor) y Tella, A. di (Director) (2015). 327 cuadernos [Cinta documental cinematográfica]. Argentina, Chile: Gema Films, Lupe Films.

Lauzirika, C. d., y Deeley, M. (Productores), y Scott, R. (Director) (1982). Blade Runner [Cinta cinematográfica]. Estados Unidos. The Ladd Company et al.

Lem, S (1973). Memoirs found in a Bathtub. New York: The Continuum Publishing Corporation.

Orwell, G. (1949). Nineteen Eighty-Four. London: Secker \& Warburg.

Piglia, R. (1967). La invasión. Buenos Aires: Jorge Álvarez.

Piglia, R. (1980). Respiración artificial. Buenos Aires: Pomaire.

Piglia, R. (1993a). Crítica y ficción. Barcelona: Anagrama.

Piglia, R. (1993b). La Argentina en pedazos. Buenos Aires: Ediciones de la Urraca. 
Piglia, R. (1999). Formas breves. Buenos Aires: Temas Grupo Editorial.

Piglia, R. (2001). Teoría del complot. Recuperado de http://www.casa.co.cu/publicaciones/ revistacasa/245/ricardopiglia.pdf [publicada en 2006 en Revista de la Casa de las Américas, (245), 32-41].

Piglia, R. (2005). El último lector. Buenos Aires: Anagrama.

Piglia, R. (2010). La ciudad ausente. Barcelona: Anagrama.

Piglia, R. (2015a). La forma inicial. Conversaciones en Princeton. Buenos Aires: Eterna Cadencia Editora.

Piglia, R. (2015b). Los diarios de Emilio Renzi I. Años de formación. Barcelona: Anagrama.

Piglia, R. (2015c). Por un relato futuro: conversaciones con Juan José Saer. Barcelona: Anagrama.

Piglia, R. (2016a). Escritores norteamericanos. Buenos Aires: Tenemos las Máquinas.

Piglia, R. (2016b). Las tres vanguardias: Saer, Puig, Walsh. Buenos Aires: Eterna Cadencia.

Piglia, R. (2016c). Los diarios de Emilio Renzi II. Los años felices. Barcelona: Anagrama.

Piglia, R. (2017). Los diarios de Emilio Renzi III. Un día en la vida. Barcelona: Anagrama.

Piglia, R. (Ed.) (2000). Diccionario de la novela de Macedonio Fernández. México: D. F: Fondo de Cultura Económica de Argentina.

Pommer, E. (Productor) y Lang, F. (Director) (1927). Metropolis [Cinta cinematográfica]. Alemania’: Universum Film (UFA).

Real Academia Española (RAE) (2010). Distopía. Recuperado de http://dle.rae.es/?id=DyzvRef

Shelley, M. (1818). Frankenstein or the Modern Prometheus. London: Lackington, Hughes, Harding, Mavor, \& Jones.

Verne, J. (1892). Le château des Carpathes. Paris: J. Hetzel et Compagnie.

Villers de L'isle Adam, A. (1886). L'Ève Future. Paris: M. de Brunhoff Editeur.

Von Harbou, T. (1926). Metropolis. Berlin: August Scherl. 